\title{
Assessment of combating-desertification strategies using the linear assignment method
}

\author{
Mohammad Hassan Sadeghravesh ${ }^{1}$, Hassan Khosravi ${ }^{2}$, and Soudeh Ghasemian ${ }^{2}$ \\ ${ }^{1}$ Department of Environment, College of Agriculture, Takestan Branch, Islamic Azad University, Takestan, Iran \\ ${ }^{2}$ Department of Arid and Mountainous Reclamation Region, Faculty of Natural Resources, \\ University of Tehran, Tehran, Iran \\ Correspondence to: Hassan Khosravi (hakhosravi@ut.ac.ir)
}

Received: 20 December 2015 - Published in Solid Earth Discuss.: 18 January 2016

Revised: 2 April 2016 - Accepted: 5 April 2016 - Published: 27 April 2016

\begin{abstract}
Nowadays desertification, as a global problem, affects many countries in the world, especially developing countries like Iran. With respect to increasing importance of desertification and its complexity, the necessity of attention to the optimal combating-desertification alternatives is essential. Selecting appropriate strategies according to all effective criteria to combat the desertification process can be useful in rehabilitating degraded lands and avoiding degradation in vulnerable fields. This study provides systematic and optimal strategies of combating desertification by use of a group decision-making model. To this end, the preferences of indexes were obtained through using the Delphi model, within the framework of multi-attribute decision making (MADM). Then, priorities of strategies were evaluated by using linear assignment (LA) method. According to the results, the strategies to prevent improper change of land use $\left(A_{18}\right)$, development and reclamation of plant cover $\left(A_{23}\right)$, and control overcharging of groundwater resources $\left(A_{31}\right)$ were identified as the most important strategies for combating desertification in this study area. Therefore, it is suggested that the aforementioned ranking results be considered in projects which control and reduce the effects of desertification and rehabilitate degraded lands.
\end{abstract}

\section{Introduction}

Desertification is a significant global environmental and the socioeconomic problem in the world (Miao et al., 2015). Desertification is defined as a process of land degradation in arid, semi-arid and sub-humid areas due to various factors including climatic variations and human activities (Barbero-Sierra et al., 2015). Land degradation and its vicious form in arid and semi-arid lands, desertification, are still widespread - jeopardizing livelihoods and sustainable development (Fleskens and Stringer, 2014). They affect vulnerable populations and fragile ecosystems with irreversible outcomes (Bisaro et al., 2014). According to the United Nations Conference on Desertification (UNCOD), the desertification process threatens more than 785 million people living in arid regions. Of this number, 60 to 100 million people are affected by this phenomenon directly due to the loss of land fertility and other desertification processes (Meshkat, 1998). There are 100 million hectares in Iran facing desertification, especially wind erosion, water erosion and physicochemical destruction (Forest, Rangeland and Watershed Institute, 2005). Strong communication between scientific knowledge and stakeholders is needed to slow down and reverse the impacts of land degradation on drylands (Barbero-Sierra et al., 2015).

Combating desertification includes activities that are part of the integrated development of land in arid, semi-arid and dry sub-humid areas for sustainable development, aimed at the (i) prevention and/or reduction of land degradation, (ii) rehabilitation of partly degraded land and (iii) reclamation of desertified land (Law Office of Environment and Parliamentary Affairs, 2004). By taking this framework into account, this study tries to present a systematic method for providing effective solutions among the several solutions based on different desertification criteria. Therefore, in order to achieve this goal, decision-making models and the linear as- 
signment (LA) method were used to rank desertification alternatives.

Managing desert ecosystems consist of various managements to control desertification phenomenon and minimize economic, social and environmental loss. Making decisions about the management of desert areas becomes a complex process due to the existence of various indexes and various criteria for decision-making in such areas. There are several methods for managing desert regions, and each has different preferences for environmental, social, political, economic and organizational issues. Among these different methods, multi-attribute decision making (MADM) can provide the best answers in comparison to others. The purpose of this study, by considering limitation of inputs, is to assess desertification strategies to achieve the optimal strategies in the framework of sustainable management of desert area. To achieve this goal, the LA method, which is one kind of concordance method, was used in the framework of MADM to rank combating-desertification strategies. This method has a simple algorithm that can engage simultaneously a large number of quantitative and qualitative criteria in the decision-making process. Additionally, in different intervals of time and place, it is also capable of changing the input data and providing new assessments according to this change. Therefore, comparative studies would be easy to do (Asgharpour, 1999).

LA has two advantages: first being descriptive and second being easy to understand. Therefore, it has been applied in various fields of science (Bernardo and Blin, 1977). Some of these studies include assessing environmental sustainability (Hosseinzadeh et al., 2011), assessing and ranking risks (Sayadi et al., 2011), monitoring sensitivity of desertification (Symeonakis et al., 2014), footprint of research in desertification management (Miao et al., 2015), characterization and interaction of driving factors in desertification (Xu and Zhang, 2014), identifying susceptible areas toward desertification (Vieira et al., 2015), evaluation of soil fertility in the succession of karst rocky desertification (Xie et al., 2014), assessing environmental sensitivity of areas toward desertification (Sobhand and Khosravi, 2015), financial assessment of companies (Mohammadi, 2011), assessing strategies of water supply (Mianabadi and Afshar, 2008), zoning watersheds (Ramesht and Arabameri, 2012), assigning water resources in order to minimize the energy consumption (Joung et al., 2012), programming of robots (Ji et al., 1992), programming the dispatch of helicopters in emergency missions (Celi, 2007) and so on and so forth.

By studying the research literature using decision models to provide optimal strategies in desert management is limited to research of Grau et al. (2010), Sadeghiravesh et al. $(2010,2013,2014,2016)$ and Sepehr and Peroyan (2011). In order to select the optimal strategies for providing an integrated plan to control erosion and desertification, Grau used three decision models in his research: Elimination and Choice Expressing Reality (ELECTRE), analytical hierar- chy process (AHP) and Preference Ranking Organization Method For Enrichment Evaluation (PROMETHEE) (Grau et al., 2010). The results indicate the high efficiency of these models to provide an optimal strategy of desertification. Due to the use of complex methods in each model, the results were largely the same. Sadeghiravesh et al. prioritize the strategies in the Khezrabad region by using the following models: AHP (Sadeghiravesh et al., 2010), ELECTRE (Sadeghiravesh et al., 2014), weighted sum model (WSM) (Sadeghiravesh and Zehtabian, 2013), BORDA (Sadeghiravesh, 2014), PERMUTATION (Sadeghiravesh, 2013), and PROMETHEE (Sadeghiravesh et al., 2016). The results of these studies are the same and largely similar to the results of previous research. Sepehr and Peroyan zoned the vulnerability of desertification in the ecosystems of the Khorasan Razavi Province and evaluated these strategies to combat desertification (Sepehr and Peroyan, 2011).

All in all, determining effective combating-desertification alternatives and criteria is essential for achieving efficient projects to combat desertification. Hence, this research uses the linear assignment method to objectively select the optimal combating-desertification alternatives based on the results of interviews with experts in the Khezrabad region in Yazd province, Iran, as the case study.

\section{Material and methods}

\subsection{Study area}

The Khezrabad region in Yazd province, central Iran, was chosen for optimal determination of alternatives to combat desertification. The study area is located nearly $10 \mathrm{~km}$ west of Yazd. The region extends from $53^{\circ} 55^{\prime}$ to $54^{\circ} 20^{\prime} \mathrm{E}$ in longitude and from $31^{\circ} 45^{\prime}$ to $32^{\circ} 15^{\prime} \mathrm{N}$ in latitude and covers an area of about 78180 ha (Fig. 1). The climate of the study area is cold and arid, based on the Amberje climate classification method (Sadeghiravesh, 2008). About 12930 ha (16\%) of the region is hilly, and a sand-dune area ${ }^{1}$, which is a part of the Ashkezar Great $\mathrm{Erg}^{2}$, is located in the northern part of the study area. About 9022 ha (12\%) of the area consists of bare lands, clay plain and desert pavement ${ }^{3}$ (Sadeghiravesh, 2008; Kazemi Nejad, 1996). About 1995 ha (26.5\%) of all the agricultural land in the region consists of degraded or abounded lands with human activities such as traditional irrigation and natural processes like wind erosion and dust. The study area shows an absolutely typical condition of desertification, so effective solutions and optimal means of combating desertification must be pursued.

\footnotetext{
${ }^{1}$ An isolated hill, knob, ridge, outcrop or small mountain.

${ }^{2}$ An erg (also sand sea or dune sea, or sand sheet if it lacks dunes) is a broad, flat area of desert covered with wind-swept sand.

${ }^{3}$ A desert surface covered with closely packed, interlocking angular or rounded rock fragments of pebble and cobble size.
} 

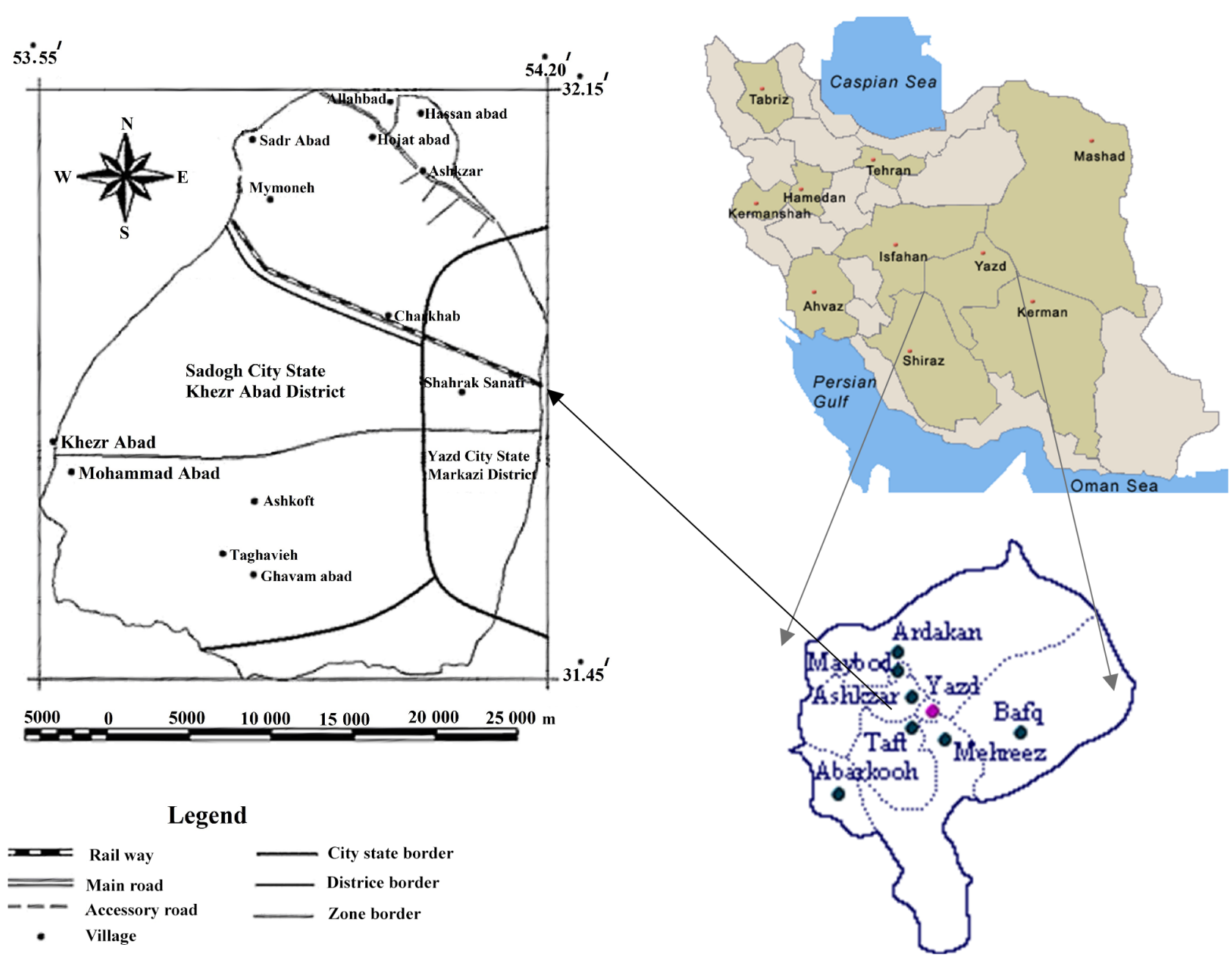

Figure 1. Location of the study area.

\subsection{Methodology}

Linear assignment is one of the most important methods of MADM and a subset of concordance methods. LA can help decision makers choose the best option by combining qualitative and quantitative indexes and providing appropriate weighting for each criterion. The output of this model is a collection of ranks, so it provides the required coordination in the most suitable way. In this method, given choices of moot point are ranked according to their scores on each index and the final ranking of the alternatives will be characterized through linear compensation processing (for every possible interaction between indexes) (Asgharpour, 1999). Based on the property simplex solution space of LA, the optimum solution is extracted in a convex space simplex and by considering all the arrangements implicitly. Moreover, the compensation property of the indexes is obtained from exchange between ranks and options (Pomerol and Romero, 2000); however, the weight vector of indexes has been obtained through expert opinion and the Delphi model.

\subsubsection{Selection of criteria and effective strategies}

Selecting criteria and alternatives can be done individually according to expert experience, resources, field studies and the Delphi method. To this aim, the structured questionnaire, in two parts including 16 criteria and 40 alternatives, was distributed among experts familiar with the study area. The experts were asked to rate effective criteria and alternatives between 0 and 9 . Finally, arithmetical mean was used to calculate the mean of obtained results, and mean values were calculated. In this case, if the mean value was less than 7 $(\bar{X}<7)$, related criteria and alternatives were removed; if the mean value was more or equal to $7(\bar{X} \geq 7)$, related criteria and alternatives were used as effective criteria (Azar and Rajabzadeh, 2002; Azar and Memariani, 2003). Tables 1 and 8 show the recommended alternatives, offering criteria. 
Table 1. The criteria and their importance mean according to the group.

\begin{tabular}{|c|c|c|c|c|c|c|}
\hline Code & $C_{1}$ & $C_{2}$ & $C_{3}$ & $C_{4}$ & $C_{5}$ & $C_{6}$ \\
\hline Criteria & $\begin{array}{l}\text { Expense- } \\
\text { benefit }\end{array}$ & Time & $\begin{array}{l}\text { Participation } \\
\text { of local } \\
\text { communities }\end{array}$ & $\begin{array}{l}\text { Beauty of } \\
\text { landscape }\end{array}$ & $\begin{array}{l}\text { Access to the } \\
\text { technologies } \\
\text { and scientific } \\
\text { methods and } \\
\text { devices }\end{array}$ & $\begin{array}{l}\text { Access to the } \\
\text { related expert }\end{array}$ \\
\hline Code & $C_{7}$ & $C_{8}$ & $C_{9}$ & $C_{10}$ & $C_{11}$ & $C_{12}$ \\
\hline Criteria & $\begin{array}{l}\text { Proportion and } \\
\text { adaptation to } \\
\text { the } \\
\text { environment } \\
\text { (sustainability) }\end{array}$ & $\begin{array}{l}\text { Traditional } \\
\text { management } \\
\text { and local } \\
\text { knowledge }\end{array}$ & $\begin{array}{l}\text { Democratic } \\
\text { government } \\
\text { authority in } \\
\text { combating- } \\
\text { desertification } \\
\text { projects }\end{array}$ & $\begin{array}{l}\text { Oil income of } \\
\text { government }\end{array}$ & $\begin{array}{l}\text { Temporary } \\
\text { management } \\
\text { of projects }\end{array}$ & $\begin{array}{l}\text { The problems } \\
\text { resulted from } \\
\text { innovation and } \\
\text { method } \\
\text { changes }\end{array}$ \\
\hline Code & $C_{13}$ & $C_{14}$ & $C_{15}$ & $C_{16}$ & & \\
\hline Criteria & $\begin{array}{l}\text { Indolence state } \\
\text { administrative } \\
\text { systems }\end{array}$ & $\begin{array}{l}\text { Social and } \\
\text { political } \\
\text { pressures }\end{array}$ & $\begin{array}{l}\text { Emergency } \\
\text { issues related to } \\
\text { desertification } \\
\text { occurrence }\end{array}$ & $\begin{array}{l}\text { Destruction of } \\
\text { resources, } \\
\text { human and } \\
\text { social damages }\end{array}$ & & \\
\hline
\end{tabular}

Table 2. Importance and priority degree according to the nine-point Saaty scale.

\begin{tabular}{lll}
\hline Score & Importance degree & $\begin{array}{l}\text { Priority degree in } \\
\text { pairwise comparison }\end{array}$ \\
\hline 1 & Non-importance & Equal \\
2 & Very low & Equal-moderately \\
3 & Low & Moderately \\
4 & Relatively low & Moderately-strongly \\
5 & Medium & Strongly \\
6 & Relatively high & Strongly-very strongly \\
7 & High & Very strongly \\
8 & Very high & Very strongly-extremely \\
9 & Excellent & Extremely \\
$1 / 2,1 / 3,1 / 4, \ldots, 1 / 9$ & Mutual values & \\
\hline
\end{tabular}

\subsubsection{Calculation of local priority of criteria and alternatives and establishment of group pairwise comparison matrix}

In order to achieve local priority, the structured questionnaire was designed based on literature and the nine-point Saaty scale: 1 (least important) to 9 (most important). They were used to measure the relative importance of criteria and priority of combating-desertification alternatives (Table 2).

The questionnaire was distributed among experts familiar with the study area. Using geometric mean and assumption of expert's opinion (considering all opinions have same value), pairwise comparisons matrixes were obtained according to Eq. (1) and formed in a group format (Table 3).

$\bar{a}_{i j}=\left(\pi_{k=1}^{N} a_{i j}^{k}\right)^{\frac{1}{N}}$
Table 3. Pairwise comparisons matrix.

$A=$\begin{tabular}{cccc}
$a_{11}$ & $a_{12}$ & $\ldots$ & $a_{1 n}$ \\
$a_{21}$ & $a_{22}$ & $\ldots$ & $a_{2 n}$ \\
$\vdots$ & $\vdots$ & $\vdots$ & $\vdots$ \\
$a_{n 1}$ & $a_{n 2}$ & $\ldots$ & $a_{n n}$ \\
\hline
\end{tabular}

$a_{i j}$ is the preference of $i$ criteria to $j$ criteria.

In this equation, $a_{i j} k$ is the component of $k$ expert to comparison $i$ and $j$. So, $\bar{a}_{i j}$ (geometric mean) for all corresponding components is obtained by Eq. (1) (Azar and Rajabzadeh, 2002; Ghodsipour, 2002).

\subsubsection{Computation of the priorities based on group pairwise comparison tables}

At this stage, the data of group pairwise comparison matrixes were imported in EC software to evaluate criterion, importance and alternative priorities to each criterion (Godsipour, 2002). After normalization by using Eq. (2) importance and priorities percent were showed as bar graphs using the harmonic mean method or average of each level of normalized matrix (Tables 5 and 6).

$\bar{r}_{i j}=\frac{\bar{a}_{i j}}{\sum_{i=1} \bar{a}_{i j}}$

In this equation, $\bar{r}_{i j}$ is the normal component, $\bar{a}_{i j}$ is the group pairwise comparison component of $i$ to $j$ and $\Sigma \bar{a}_{i j}$ is the total column of group pairwise comparisons. 
Table 4. Normalized decision matrix.

\begin{tabular}{cccccc}
\hline Alt & \multicolumn{5}{c}{ Criterion } \\
\hline$C_{1}$ & $C_{2}$ & $C_{3}$ & $\ldots$ & $C_{n}$ \\
\cline { 2 - 6 }$W_{1}$ & $W_{2}$ & $W_{3}$ & $\ldots$ & $W_{n}$ \\
\hline$A_{1}$ & $P_{11}$ & $P_{12}$ & $P_{13}$ & $\ldots$ & $P_{1 n}$ \\
$A_{2}$ & $P_{21}$ & $P_{22}$ & $P_{23}$ & $\ldots$ & $P_{2 n}$ \\
$\vdots$ & $\vdots$ & $\vdots$ & $\vdots$ & $\vdots$ & $\vdots$ \\
$A_{m}$ & $P_{m 1}$ & $P_{m 2}$ & $P_{m 3}$ & $\ldots$ & $P_{m n}$ \\
\hline
\end{tabular}

In this matrix, $m$ is the number of choices or alternatives, $n$ is number of criteria, $C$ is the title of criteria, $W$ is the weight value of related criteria and $a_{i j}$ is the weight value each alternative gains in relation to related criteria.

\subsubsection{Formation of normalized decision matrix}

The weight values of criterion importance $\left(W_{j}\right)$ and alternative priorities $\left(P_{i j}\right)$ are considered in the form of a decision matrix based on any criteria (Table 4$)$.

\subsubsection{Ranking each option for each index}

After forming the decision-making matrix, we attempted to rank the alternatives $\left(A_{i}\right)$ for each criteria $\left(C_{i}\right)$ with respect to the increasing or decreasing trends and $n \times m$ matrix framework (Table 7).

\subsubsection{Forming two-dimensional gamma $(\gamma)$ matrix}

A two-dimensional $(\boldsymbol{\gamma})$ matrix (assignment matrix) is formed according to the weight vector of the estimated criteria of group pairwise comparison. This matrix is a square matrix $\left(\boldsymbol{\gamma}_{m \times m}\right)$ which has element $i$ in its row and element $k$ in its column. Matrix elements include the total weight of indexes, in which the alternative of $i$ has rank $k$. The $(\gamma)$ matrix is a assignment matrix, so the optimal solution can be obtained by any kind of assignment methods such as the shipping method, Hungarian method, grid method and 1-0 linear programming method. The most common method for solving the LA is the assignment programming method (Pomerol and Romero, 2000).

\subsubsection{Calculating the final rank for each alternative $\left(A_{i}\right)$}

The final ranking/optimal solution of alternatives is obtained by linear programming method and through the following model:

$\operatorname{maximize} \sum_{i=1}^{m} \sum_{k=1}^{m} \boldsymbol{\gamma}_{i k} h_{i k}$,

subject to $\sum_{k=1}^{m} h_{i k}=1 ; \quad i=1,2,3, \ldots, m$,

$$
\sum_{i=1}^{m} h_{i k}=1 b e ; \quad k=1,2,3, \ldots, m ; \quad h_{i k}\left\{\begin{array}{l}
=1 \\
=0
\end{array} .\right.
$$

After solving the linear programming model, a square matrix $\left(\mathbf{H}_{m \times m}\right)$ is considered where $A_{i}$ is given the final $k$ rank $\left(h_{i k}=1\right.$ ); otherwise $h_{i k}=0$ (Burkard and Qela, 1999; Liu, 2000)

The obvious feature of this method is a simple ranking for alternatives that caused exchanged among indexes and have no complex calculations. Also, in this method there is no need for the unification scale (Saaty and Vargas, 2006; Asgharpour, 1999). Meanwhile, other methods such as MADM need both alternatives and indexes for calculating, but ranking process of LA can be done without an alternative (Tajoddini, 2003).

\section{Results and discussion}

In the process of assessing combating-desertification alternatives in the study area, the Delphi method and questionnaire were used to identify the main criteria and alternatives among 16 criteria and 40 combating-desertification alternatives and establishing hierarchical structure (Saaty, 1995) according to the group format. Tables 8 and 9 show the average of alternative priority and criterion importance, respectively.

The obtained results of presented questionnaire (to determine importance and priority of criteria and alternatives to establish decision hierarchical structure) show only criteria and alternatives with a group mean larger than 7 . This considered establishing decision hierarchical chart and providing pairwise comparisons questionnaires. Figure 2 show hierarchical decision structure based on effective criteria and alternatives to combat desertification.

\subsection{Calculating relative weight of criteria and alternatives and formatting the group decision matrix}

In order to estimate the relative weight or priority of criteria and alternatives, a pairwise comparison questionnaire was prepared and distributed among the experts. The group pairwise comparison matrixes of criterion importance and alternative priorities to each criterion were formed by obtaining expert opinions and combining their ideas by geometric mean. To prevent the prolongation of the word, just matrixes of criterion importance (Table 10) and alternative priorities to each criteria calculated by this method are presented.

Matrix values of criterion importance and alternative priorities (Table 10) were entered into EC software based on each criterion importance of combating-desertification criteria. Alternatives were obtained in a group format. In addition, graphs were prepared based on percentage using normalization and harmonic mean (Table 11). 
Table 5. Comparison of proposed criterion importance to access the goal.

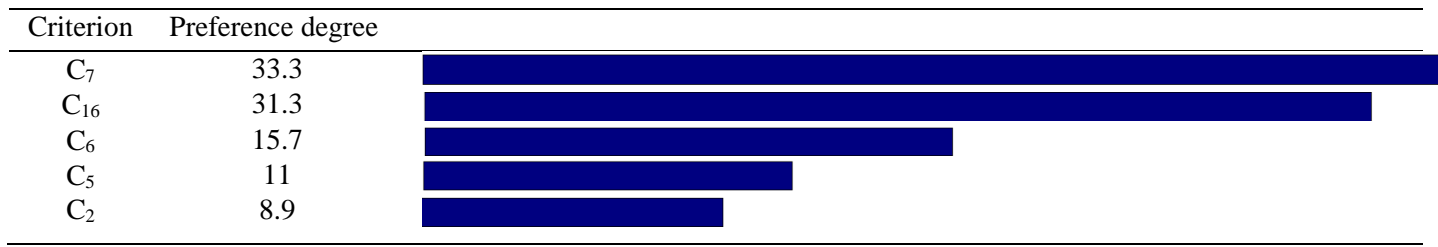

Inconsistency ratio $=0.01$

Table 6. Comparison of alternative preference according to the criteria of proportion and adaptation to the environment.

\begin{tabular}{ccc}
\hline Alternative & Degree & \\
\hline $\mathrm{A}_{18}$ & 26.6 & \\
$\mathrm{~A}_{23}$ & 22.7 & \\
$\mathrm{~A}_{31}$ & 19.2 & \\
$\mathrm{~A}_{33}$ & 15.9 & \\
$\mathrm{~A}_{20}$ & 15.5 & \\
\hline
\end{tabular}

Inconsistency ratio $=0.02$

Table 7. Matrix ranking of each option against each index.

\begin{tabular}{lccccc}
\hline Criteria $(C) \triangleright$ & $C_{1}$ & $C_{2}$ & $C_{3}$ & $\ldots$ & $C_{n}$ \\
\cline { 2 - 6 } & & & & & \\
\hline Rank $(A) \boldsymbol{\nabla}$ & $A_{11}$ & $A_{12}$ & $A_{13}$ & $\ldots$ & $A_{1 n}$ \\
First & $A_{21}$ & $A_{22}$ & $A_{23}$ & $\ldots$ & $A_{2 n}$ \\
Second & $A_{31}$ & $A_{32}$ & $A_{33}$ & $\ldots$ & $A_{3 n}$ \\
Third & & & & $\ldots$ & \\
$\ldots$ & & & & $\ldots$ & \\
$\ldots$ & $A_{m 1}$ & $A_{m 2}$ & $A_{m 3}$ & $\ldots$ & $A_{m n}$ \\
$m$ &
\end{tabular}

Considering these graphs, one can observe that the alternatives are different based on each criterion. Therefore, the decision-making matrix of optimal combating-desertification alternatives according to the group (Table 12) was formed to select final alternatives and classification of their priorities in the general framework of MADM (Table 4).

\subsection{Ranking each option for each index}

After forming the decision-making matrix, we attempted to rank the alternatives $\left(A_{i}\right)$ for each criteria $\left(C_{i}\right)$ in a $5 \times 5$ matrix in which the rows represent rank and columns represent the index (Table 13). The decision matrix of combatingdesertification alternatives has an increasing trend, which means the allocated number of each alternative is more than the number of each criterion, so that alternative is more desirable than the others.

\subsection{Forming $\gamma_{5 \times 5}$ matrix according to criterion weights $(W)$}

At this stage a $5 \times 5 \gamma$ matrix is formed, and it was estimated by the sum of index weights in which the alternative of $i$ has rank $k$. As mentioned, the weight of each index was calculated by surveying experts and based on the Delphi method (Table 14).

The $\gamma$ matrix is an assignment matrix, and the optimal answer can be obtained by any of assignment methods. The most common method for solving the linear assignment method is linear programming.

\subsection{Ranking alternatives}

For final ranking of alternatives, linear programming was used (Eqs. 1 to 3), and a scoring table of options or optimal matrix was formed (Table 11). Since the decision variable contains 0 and 1 value, the output of this program is provided only based on the number 1 in Table 15 . Table 16 was formed according to Table 15.

Based on Table 17, the preference of alternatives was obtained as $A_{18}>A_{23}>A_{31}>A_{33}>A_{20}$. After evaluating all alternatives, $A_{18}$ considered to be the best one.

\section{Discussion}

In this study a new method was presented to rank combatingdesertification alternative priority. The results of final prioritization of alternatives using LA method were similar to the results of the following methods: AHP (Sadeghiravesh et al., 2010), TOPSIS (Ivani and Sofi, 2014), ELECTRE (Sadeghiravesh et al., 2014) and WSM (Sadeghiravesh and Zehtabian, 2013). This means alternatives $A_{18}, A_{23}$ and $A_{31}$ were ranked, respectively, first to third. It should be men- 


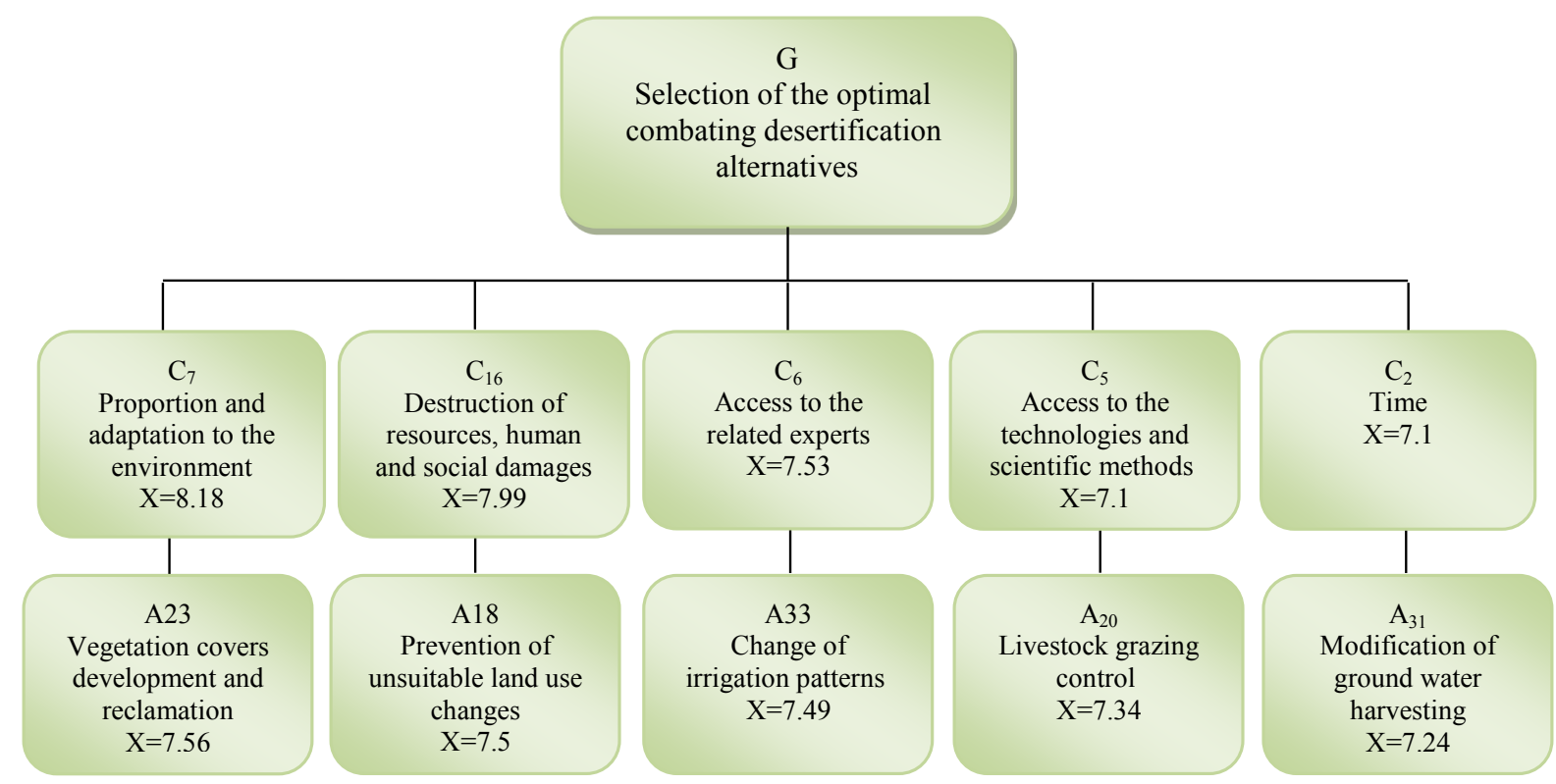

Figure 2. Hierarchical decision structure to select optimal combating-desertification alternatives in study area.

Table 8. The criteria importance mean according to the group.

\begin{tabular}{|c|c|c|c|c|c|c|c|c|c|c|c|c|c|c|c|c|}
\hline Code & $C_{1}$ & $C_{2}$ & $C_{3}$ & $C_{4}$ & $C_{5}$ & $C_{6}$ & $C_{7}$ & $C_{8}$ & $C_{9}$ & $C_{10}$ & $C_{11}$ & $C_{12}$ & $C_{13}$ & $C_{14}$ & $C_{15}$ & $C_{16}$ \\
\hline $\begin{array}{l}\text { Average } \\
\text { values }\end{array}$ & 5.38 & 7.1 & 5.78 & 5.1 & 7.1 & 7.53 & 8.15 & 5.23 & 5.28 & 5.72 & 2.39 & 2.84 & 2.29 & 5.35 & 6.34 & 7.99 \\
\hline
\end{tabular}

tioned, that the LA method has the limitation of ignoring decision makers fuzzy judgment as well as aforementioned methods. Additionally, some criteria have qualitative or unknown structures that cannot be accurately measured. In such cases, fuzzy numbers can be used in order to achieve evaluation matrix, and the prioritization method can be developed using the fuzzy method. Another disadvantage of the LA method is regarding the amount of data and considering only the data ranks. Therefore, large amounts of data are lost and achieving high-accuracy results would not be possible (Mohammadi, 2011). Consequently, it is better to not use rating models such as ELECTRE and LA when accurate amounts of data are available. The following results were obtained using pairwise comparisons questionnaires, the mean of expert opinions, group pairwise comparisons matrix of importance and priority of criteria and alternatives. According to the decision matrix's table of optimal combating-desertification alternatives (Table 12), criteria of proportion and adaptation to environment $\left(C_{7}\right)$ and time $\left(C_{2}\right)$ have the highest and lowest importance, respectively. Criterion proportion and adaptation to the environment $\left(C_{7}\right)$ with an importance degree of $33.6 \%$ and destruction of resources, human and social damages $\left(C_{16}\right)$ with $30.7 \%$ were placed in first and second order, respectively. This indicates that experts are more concerned about environmental issues, and challenges rose in environ- mental degradation. Also, these tables represent alternative priorities to each criterion. As is taken from the table, selected alternatives will be different according to each criterion. Therefore, the selection of final alternatives and ranking of their priority combinations were conducted on decision matrix by LA model; additionally, alternative priorities were formed based on a set of criteria. According to the results of the final alternative prioritization and by considering all the alternatives, execution of prevention of unsuitable land use changes $\left(A_{18}\right)$, vegetation cover development and reclamation $\left(A_{23}\right)$ and modification of groundwater harvesting $\left(A_{31}\right)$, the desertification process can be stopped and the degraded lands can be rehabilitated. Therefore, in the study area, land use changes are mainly caused by increasing population, unemployment, growth of industry and increasing urbanization. To illustrate, land use changes have largely happened in recent years because of pressure of drought and industrial growth which lead to conversion of pastures into farms and gardens. As a consequence, enormous numbers of deep and semi-deep motorized wells have been installed in the study area. Rangelands consist of 6 to $15 \%$ of the case area, which is strongly influenced by human activities in terms of cutting brush and livestock overgrazing, so that 40 to $50 \%$ of plant cover are destroyed. Irrigation in agricultural lands is mostly flooding with outdoor pools and outdoor 
Table 9. The recommended alternatives to combat desertification and their priority according to the groups.

\begin{tabular}{|c|c|c|}
\hline Code & Alternative & Value \\
\hline$A_{1}$ & Reducing population growth rates & 5 \\
\hline$A_{2}$ & Poverty alleviation & 5.68 \\
\hline$A_{3}$ & Establishment and development of rural organizations & 5.35 \\
\hline$A_{4}$ & Increasing employment & 6.7 \\
\hline$A_{5}$ & Increasing participation of local community and supporting NGOs & 6.1 \\
\hline$A_{6}$ & Application of local forces and technology in projects (local knowledge) & 6.56 \\
\hline$A_{7}$ & Training people in utilization of new methods and use of new knowledge for optimal use of resources & 6.47 \\
\hline$A_{8}$ & Approval, promotion and implementation of laws and adaptation punishments with the crime & 5.73 \\
\hline$A_{9}$ & Providing needs of local residents & 5.89 \\
\hline$A_{10}$ & Modification of unsustainable consumption patterns, changing and improving people's livelihood patterns & 5.6 \\
\hline$A_{11}$ & Considering the role of women and youth in combating-desertification process & 4.5 \\
\hline$A_{12}$ & Organization of urban areas and prevent migration & 5.23 \\
\hline$A_{13}$ & Coordination between responsible agencies and organizations in combating-desertification and environmental protection & 6.86 \\
\hline$A_{14}$ & Raising the literacy rate & 4.8 \\
\hline$A_{15}$ & Development of desert ecotourism & 5.32 \\
\hline$A_{16}$ & Multi-utilization from desert instead of mono-utilization & 5.27 \\
\hline$A_{17}$ & Allocation combating-desertification issue to the private sector & 3.79 \\
\hline$A_{18}$ & Prevention of unsuitable land use changes & 7.5 \\
\hline$A_{19}$ & Mapping land use planning and determination of desert and salt desert boundaries & 6.44 \\
\hline$A_{20}$ & Livestock grazing control & 7.34 \\
\hline$A_{21}$ & Forage production and increasing economic potential of sustainable husbandry & 6.6 \\
\hline$A_{22}$ & Prevention of plant cutting & 6.46 \\
\hline$A_{23}$ & Vegetation cover development and reclamation & 7.56 \\
\hline$A_{24}$ & Protection of Haloxylon spp. & 6.76 \\
\hline$A_{25}$ & Protection of gravel surfaces (Reg) & 6.45 \\
\hline$A_{26}$ & Prevention and reduction in heavy agricultural and industrial machinery traffic & 5.57 \\
\hline$A_{27}$ & Create living and non-living wind break for soil conservation & 6.86 \\
\hline$A_{28}$ & Improvement of soil texture & 4.66 \\
\hline$A_{29}$ & Modification of crop rotation and follow methods & 5.42 \\
\hline$A_{30}$ & Modification of ploughing, fertilization and spraying methods & 5.1 \\
\hline$A_{31}$ & Modification of groundwater harvesting & 7.24 \\
\hline$A_{32}$ & Reduction in water consumption (water-optimal consumption in farms) & 6.6 \\
\hline$A_{33}$ & Change of irrigation patterns & 7.49 \\
\hline$A_{34}$ & Changing traditional irrigation systems with low to modern systems with high efficiency & 6.53 \\
\hline$A_{35}$ & $\begin{array}{l}\text { Optimal collecting and harvesting of water resources (including rivers isolating, qanat repairing and dredging, } \\
\text { utilization of canals and streams and desalination of salty waters) }\end{array}$ & 6.64 \\
\hline$A_{36}$ & Groundwater feed & 6.08 \\
\hline$A_{37}$ & Construction of flood broadcast networks and the use of its alluviums & 5.3 \\
\hline$A_{38}$ & Creation of artificial precipitation to feed aquifers & 3.47 \\
\hline$A_{39}$ & Promotion of greenhouse cultivation & 6.2 \\
\hline$A_{40}$ & Introduction of new plant varieties, resistant to drought and dehydration stress by genetic engineering & 6 \\
\hline
\end{tabular}

Table 10. Pairwise comparisons matrix of the criterion importance to complete the goal of "offering optimal combating-desertification alternatives".

\begin{tabular}{c|cccc}
\hline Criterion & $C_{16}$ & $C_{6}$ & $C_{5}$ & $C_{2}$ \\
\hline$C_{7}$ & 1.2 & 2.5 & 2.5 & 3.4 \\
$C_{16}$ & & 2.3 & 3.1 & 3.1 \\
$C_{6}$ & & & 1.7 & 2 \\
$C_{5}$ & & & & 1.3 \\
\hline
\end{tabular}

streams with large pores in bed; therefore, more than $50 \%$ of water's consumption is wasted and the efficiency of irrigation and transmission is estimated to be less than $40 \%$.

\section{Conclusions}

In this research the LA method was used to give optimum alternatives for combating desertification. In accordance with the results, prevention of unsuitable land use changes was estimated as the most important strategy in the study area. Additionally, other alternatives such as vegetation cover development and reclamation and balancing charging of groundwater resources were were considered subsequent priorities. 
Table 11. Comparison of proposed criterion importance to access the goal.

\begin{tabular}{ccc}
\hline Criterion & $\begin{array}{c}\text { Preference } \\
\text { degree }\end{array}$ & \\
\hline $\mathrm{C}_{7}$ & 33.3 & \\
$\mathrm{C}_{16}$ & 31.3 & \\
$\mathrm{C}_{6}$ & 15.7 & \\
$\mathrm{C}_{5}$ & 11 & \\
$\mathrm{C}_{2}$ & 8.9 & \\
\hline Inconsistency ratio $=0.01$ & \\
\hline
\end{tabular}

Table 12. Decision matrix of optimal combating-desertification alternatives according to group.

\begin{tabular}{lccccc}
\hline Criterion importance $(C) \triangleright$ & $C_{2}$ & $C_{5}$ & $C_{6}$ & $C_{16}$ & $C_{7}$ \\
\cline { 2 - 6 } Alternatives priority $(A) \boldsymbol{\nabla}$ & & & & & \\
\hline & 0.0892 & 0.1095 & 0.1576 & 0.3074 & 0.3365 \\
$A_{23}$ & 0.2509 & 0.2387 & 0.2488 & 0.1805 & 0.2257 \\
$A_{18}$ & 0.1960 & 0.1635 & 0.1983 & 0.2383 & 0.2643 \\
$A_{33}$ & 0.1620 & 0.2565 & 0.2093 & 0.1510 & 0.1599 \\
$A_{20}$ & 0.2229 & 0.1762 & 0.1608 & 0.2209 & 0.1582 \\
$A_{31}$ & 0.1682 & 0.1633 & 0.1826 & 0.2092 & 0.1918 \\
\hline
\end{tabular}

Table 13. Matrix of alternative ranking.

\begin{tabular}{lccccc}
\hline Criteria $(C) \vee$ & $C_{7}$ & $C_{16}$ & $C_{6}$ & $C_{5}$ & $C_{2}$ \\
\cline { 2 - 6 } Rank $(A) \boldsymbol{\nabla}$ & & & & & \\
\hline First & $A_{18}$ & $A_{18}$ & $A_{23}$ & $A_{33}$ & $A_{23}$ \\
Second & $A_{23}$ & $A_{20}$ & $A_{33}$ & $A_{23}$ & $A_{20}$ \\
Third & $A_{31}$ & $A_{31}$ & $A_{18}$ & $A_{20}$ & $A_{18}$ \\
Fourth & $A_{33}$ & $A_{23}$ & $A_{31}$ & $A_{18}$ & $A_{31}$ \\
Fifth & $A_{20}$ & $A_{33}$ & $A_{20}$ & $A_{31}$ & $A_{33}$ \\
\hline
\end{tabular}

Table 14. The matrix of number time weight of ranking options.

\begin{tabular}{lrrrrr}
\hline Rank $(C) \downarrow$ & First & Second & Third & Fourth & Fifth \\
\cline { 2 - 6 } $\begin{array}{l}\text { Alternative } \\
\text { priority }(A) \boldsymbol{\nabla}\end{array}$ & & & & & \\
\hline$A_{23}$ & 0.2468 & 0.446 & 0 & 0.3074 & 0 \\
$A_{18}$ & 0.6439 & 0 & 0.2468 & 0.1095 & 0 \\
$A_{33}$ & 0.1095 & 0.1576 & 0 & 0.3365 & 0.3966 \\
$A_{20}$ & 0 & 0.3966 & 0.1095 & 0 & 0.4941 \\
$A_{31}$ & 0 & 0 & 0.6439 & 0.2468 & 0.1095 \\
\hline
\end{tabular}

Hence, in the framework of macro-strategies executive offers are recommended in the following:

- taking serious spatial planning and estimating ecological potential at national, regional and local levels and adapting the applications to the land potential

- avoiding land use changes in poor rangelands with low fertility
Table 15. The options scoring.

$*=H \quad \mid$\begin{tabular}{lllll}
\hline & 1 & 0 & 0 & 0 \\
1 & 0 & 0 & 0 & 0 \\
0 & 0 & 0 & 0 & 1 \\
0 & 0 & 0 & 0 & 1 \\
0 & 0 & 1 & 0 & 0 \\
\hline
\end{tabular}

The optimal objective function $=2.6245$.

Table 16. The matrix of options optical order.

\begin{tabular}{c|ccccc}
\hline \multirow{4}{*}{$A=^{*} \times H$} & 0 & $A_{18}$ & 0 & 0 & 0 \\
$A_{23}$ & 0 & 0 & 0 & 0 \\
0 & 0 & 0 & 0 & $A_{31}$ \\
0 & 0 & 0 & 0 & $A_{33}$ \\
0 & 0 & $A_{33}$ & 0 & 0 \\
\hline
\end{tabular}

- avoid the development of industries in sensitive and fragile regions

- in terms of development and reclamation of vegetation, it is better to use endemic and resistant species and pressurized irrigation systems

- balance the number of livestock and pasture capacity

- avoid grazing off-season in desert rangelands (early and late grazing) due to degradation of poor vegetation.

The results of this research can be used in future investments aiming to obtain a sustainable development, so that the marginal ecosystems and investments in arid and semiarid region will be protected. Allocated investments for arid 
Table 17. The options ranking.

\begin{tabular}{lllll}
\hline$A_{18}$ & $A_{23}$ & $A_{31}$ & $A_{33}$ & $A_{20}$ \\
\hline
\end{tabular}

regions are limited; thus, arid land managers should take the results of this research into account for preventing any waste of those limited investments.

Finally, it is recommended that all combatingdesertification projects in the study area be done based on all aforementioned alternatives. In this case, less investment would be wasted and the efficiency of such rehabilitation projects may increase. The results of this study will allow desert managers to apply limited investment and facilities in efficient ways to control the process of desertification. Hence, we can achieve better results and avoid wasting national investments.

Edited by: A. Cerdà

\section{References}

Asgharpour, M. J.: Multiple criteria decision making, University of Tehran, Tehran, p. 397, 1999.

Azar, A. and Memariani, A.: AHP new technique for group decision, Knowledge Management Magazine, 28, 22-32, 2003.

Azar, A. and Rajabzadeh, A.: Applied decision making, Tehran, Negahe Danesh, 1st Edn., p. 185, 2002.

Barbero-Sierra, C., Marques, M. J., Ruiz-Pérez, M., Escadafal, R., and Exbrayat, W.: How is Desertification Research Addressed in Spain? Land Versus Soil Approaches, Land Degrad. Dev., 26, 423-432, 2015.

Bernardo, J. J. and Blin, J. M.: A programming model of consumer choice among multi-attributed brands, J. Consum. Res., 4, 111118, 1977.

Bisaro, A., Kirk, M., Zdruli, P., and Zimmermann, W.: Global drivers setting desertification research priorities: Insights from a stakeholder consultation forum, Land Degrad. Dev., 25, 5-16, 2014.

Burkard, R. E. and Qela, E.: Linear assignment problems and extensions, in Handbook of Combinatorial Optimization, Springer, 75-149, 1999.

Celi, R.: Rotorcraft dispatching in large-scale emergencies using sequential linear assignment techniques, Presented at the at the AHS 63rd Annual Forum, Virginia Beach, VA, 2-4 May, 2007.

Fleskens, L. and Stringer, L. C.: Land management and policy responses to mitigate desertification and land degradation, Land Degrad. Dev., 25, 1-4, 2014.

Forest, Rangeland and Watershed Institute: summary of management program of Iran desert area (2005-2024), 61 pp., 2005.

Ghodsipour, S. H.: Analytical Hierarchy Process (AHP), Amirkabir University, Tehran, 220 pp., 2002.

Grau, J. B., Antón, J. M., Tarquis, A. M., Colombo, F., de los Ríos, L., and Cisneros, J. M.: An application of mathematical models to select the optimal alternative for an integral plan to desertification and erosion control (Chaco Area - Salta Province
- Argentina), Biogeosciences, 7, 3421-3433, doi:10.5194/bg-73421-2010, 2010.

Hosseinzadeh, S. Y., Khosravibaygi, R., Istageldi, M., and Shamsodini, R.: An assessment of environmental assessment of urban area Using the technique of linear allocation Multiple Criteria Decision Makin (Case study: Bandar-e Turkaman city, Iran), J. Geogr. Land., 16, 31-51, 2011.

Ivani, H. and Sofi, M.: Assessment of Regional Development Using Taxonomy Model (A Case of Razavi Khorasan, Iran), Am. J. Eng. Res., 3, 12-17, 2014.

Ji, Z., Leu, M. C., and Wong, H.: Application of Linear Assignment Model for Planning of Robotic Printed Circuit Board Assembly, J. Electron. Packag., 114, 455-460, 1992.

Joung, J., Keong Ho, C., Hui Tan, P., and Sun, S.: Energy Minimization in OFDMA Downlink Systems: A Sequential Linear Assignment Algorithm for Resource Allocation, IEEE Wireless Commun. Lett., 1, 300-303, 2012.

Kazemi Nejad, A.: The study of sand dune movement, M.Sc. thesis, University of Tehran, 1996.

Law Office of Environment and Parliamentary Affairs: International Contract, Laws and regulations the environment protection, Publication of Environment Organization, 847 pp., 2004.

Liu, S. C.: A Fuzzy Multiple Attribute Decision Making Approach for Linear Assignment Problems, Fifth Asia Pacific Decision Sciences Institute Conference Waseda University, Tokyo, Japan, 24 27 July, 2000.

Meshkat, M. A.: Integrated methods for monitoring and assessing desertification, publication of Forest, Rangeland and Watershed Institute, 145 pp., 1998.

Mianabadi, H. and Afshar, A.: Multi attribute decision making to rank urban water supply schemes, Water \& Wastewater Journal, 19, 34-45, 2008.

Miao, L., Moore, J. C., Zeng, F., Lei, J., Ding, J., He, B., and Cui, X.: Footprint of Research in Desertification Management in China, Land Degrad. Dev., 26, 450-457, 2015.

Mohammadi, A.: A comparative applied study of linear allocation TOPSIS method and Taxonomy in financial evaluation, Economic Research, 11, 273-302, 2011.

Pomerol, J. C. and Romero, S. B.: Multi-Criterion Decision in Management: Principles and practice, International Series in Operations Research \& Management Science, the Netherlands, Kluwer Academic, Dordrecht, 2000.

Ramesht, M. H. and Arabameri, A. R.: Shahrood-Bastam Basin Zoning for the Purpose of Artificial Underground Aquifer Recharge by Using Linear Assignment Method and GIS Technique, Geographic Space, 40, 134-149, 2012.

Saaty, T. L.: Decision making for leaders: The Analytic Hierarchy Process for Decision in a complex world, vo1 H, Rws, 1995.

Saaty, T. L. and Vargas, L. G.: Decision, making with the Analytic Network Process: Economic, Political, Social and Technological Applications with Benefits, Opportunities, Costs and Risks, New York, Springer, 2006.

Sadeghiravesh, M. H.: the research of desertification effective factors in environmental destroy (case study: Khezr Abad Zone, Environmental Management thesis, Islamic Azad University, 395 pp., 2008.

Sadeghiravesh, M. H.: Assessment of Combat Desertification Alternatives Using Permutation method, case study: Khezr Abad region, Yazd province, J. Environ. Plan. Manage., 10, 1-10, 2013. 
Sadeghiravesh, M. H.: Evaluation of combat desertification alternatives by using BORDA ranking model, Case study: Khezr Abad region, Yazd province, J. Environ. Plan. Manage., 1, 1324, 2014.

Sadeghiravesh, M. H. and Zehtabian, G.: Combat desertification alternatives classification with using of Multi Attribute Decision Making (MADM) view point and Weighted Sum Model (WSM), Case study: Khezr Abad region, Yazd province, Journal of Pajouhesh \& Sazandeghi, 100, 1-11, 2013.

Sadeghiravesh, M. H., Ahmadi, H., Zehtabian, G. H., and Tahmores, M.: Application of analytical hierar- chy process (AHP) in assessment of dedesertification alternatives, case study: Khezrabad region, Yazd province, Iranian Journal of Range and Desert Research, 17, 35-50, 2010.

Sadeghiravesh, M. H., Zehtabian, G. R., Ahmadi, H., and Khosravi, H.: Using Analytic Hierarchy Process method and Ordering Technique to Assess Combating desertification Alternatives (Case study: Khezrabad, Yazd, Iran), Carpath. J. Earth Env. Sci., 7, 51-60, 2013.

Sadeghiravesh, M. H., Zehtabian, G., and Khosravi, H.: Application of AHP and ELECTRE models for assessment of combating desertification alternatives, Desert, 19, 141-153, 2014.

Sadeghiravesh, M. H., Khosravi, H., Abolhasani, A., and Shekoohi, S.: Evaluation of Combating Desertification Alternatives using PROMETHEE Model, J. Geogr. Geol., 8, 28-41, 2016.

Sayyadi, A. R., Hayati, M., and Azar, A.: Assessment and Ranking of Risks in Tunneling Projects Using Linear Assignment Technique, Int. J. Ind. Eng. P. Manage., 22, 27-38, 2011.
Sepehr, A. and Peroyan, N.: vulnerability Mapping of desertification and combat desertification alternative ranking in Korasane-razavi province ecosystems with application PROMETHEE model, J. Earth Sci. Res., 8, 58-71, 2011.

Sobhani, A. and Khosravi, H.: Assessing Environmental Sensitivity Areas to Desertification in North of Iran, Curr. World Environ., 10, 890-902, 2015.

Symeonakis, E., Karathanasis, N., Koukoulas, S., and Panagopoulos, G.: Monitoring sensitivity to land degradation and desertification with the environmentally sensitive area index: The case of lesvos island, Land Degrad. Dev., doi:10.1002/ldr.2285, 2014.

Tajoddini, I.: Identification and prioritization of quality standard Prerequisites in industry, Modiriat Farda, 2, 82-88, 2003.

Vieira, R. M. S. P., Tomasella, J., Alvalá, R. C. S., Sestini, M. F., Affonso, A. G., Rodriguez, D. A., Barbosa, A. A., Cunha, A. P. M. A., Valles, G. F., Crepani, E., De Oliveira, S. B. P., De Souza, M. S. B., Calil, P. M., De Carvalho, M. A., Valeriano, D. M., Campello, F. C. B., and Santana, M. O.: Identifying areas susceptible to desertification in the Brazilian northeast, Solid Earth, 6, 347-360, doi:10.5194/se-6-347-2015, 2015.

Xie, L. W., Zhong, J., Chen, F. F., Cao, F. X., Li, J. J., and Wu, L. C.; Evaluation of soil fertility in the succession of karst rocky desertification using principal component analysis, Solid Earth, 6, 515-524, doi:10.5194/se-6-515-2015, 2015.

$\mathrm{Xu}$, E. Q. and Zhang, H. Q.: Characterization and interaction of driving factors in karst rocky desertification: A case study from Changshun, China, Solid Earth, 5, 1329-1340, doi:10.5194/se-51329-2014, 2014. 